\title{
Contradições e assimetrias na construção do conhecimento em Aids/HIV
}

\author{
Contradictions and asymmetries in the \\ construction of knowledge about Aids/HIV
}

\author{
Maria Cristina da Costa Marques \\ Pesquisadora em história da saúde e \\ professora da Faculdade de Saúde Pública (USP) \\ Rua da Consolação, 3235/92 \\ 1416-001 São Paulo - SP - Brasil \\ mcmarques@uol.com.br
}

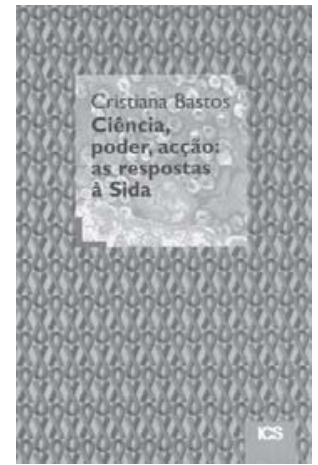

Cristiana Bastos

Ciência, poder, acção: as respostas à Sida.

Lisboa: Imprensa de Ciências Sociais,

Instituto de Ciências

Sociais da

Universidade de

Lisboa, 2002. 258 p.
A leitura do livro de Cristiana Bastos, Ciência, poder, ação: as respostas à Sida, publicado em Lisboa em 2002, nos remete a um desafio apontado por Edgar Morin (2002), para a construção do saber na sociedade contemporânea:

o desafio da globalidade: isto é, a inadequação cada vez mais ampla, profunda e grave entre um saber fragmentado em elementos desconjuntados e compartimentados nas disciplinas de um lado e, de outro, entre as realidades multidimensionais, globais, transnacionais, planetárias e os problemas cada vez mais transversais, polidisciplinares e até mesmo transdisciplinares (p. 14).

No caso, a lembrança do desafio indicado por Morin é justificada por duas razões; a primeira diz respeito à pesquisa de Cristiana Bastos que deu origem a esse excelente livro, e que coloca à luz, no campo do saber relacionado à Aids/HIV, as dificuldades e limites de uma ciência hegemônica que fragmenta, seleciona parcerias e se posiciona de forma autoritária e tímida na construção de conhecimentos e na 'produção de consenso'. Todavia, é na segunda questão que reside a maior interação com o pensamento do autor francês, a saber, o trabalho intenso de pesquisa, de reflexão e de análise sobre as dimensões 'escondidas' do conhecimento produzido sobre Aids/HIV no mundo contemporâneo e globalizado, levando Cristiana Bastos a enfrentar o desafio e, de forma sensível, contribuir para um 'novo jeito' de produzir conhecimento sobre os problemas modernos ou antigos na realidade complexa da globalização.

Ciência, poder, ação: as respostas à Sida é resultado do trabalho de pesquisa de Cristiana junto ao Instituto de Ciências Sociais da Universidade de Lisboa e, como refere a autora, "foi escrito em cima de uma experiência de contínua observação das respostas à crise gerada pelo aparecimento da Sida (Aids), primeiro nos Estados Unidos, depois no Brasil, e de novo nos Estados Unidos". Uma primeira versão do livro foi lançada nos Estados Unidos em 1999, com o título Global responses to Aids: science in emergency.

O livro é organizado em seis capítulos, apresentando o percurso de análise da autora que, constantemente, faz o diálogo entre a antro- 
pologia e outras ciências. Coloca sua disciplina, a antropologia - para além do estudo local - no enfrentamento da questão de análise, a ciência perante as dimensões da Aids/HIV em sua complexidade globalizada.

O capítulo I aborda historicamente a construção do campo de conhecimento da Aids/HIV sob inúmeras perspectivas. A autora nos apresenta, através de uma rica contextualização teórica, o impacto do surgimento da Aids/HIV nos diversos campos da ciência, em especial na medicina. A relação entre os campos de conhecimento em uma realidade complexa e globalizante se traduz neste interessante estudo social da ciência.

O capítulo II nos traz um dos aspectos mais interessantes do livro: a relação entre a política de produção de conhecimento em Aids/HIV e os movimentos sociais organizados a partir do surgimento da epidemia. É nessa parte da leitura que está presente o embate entre o ativismo de grupos ligados à Aids/HIV e a ciência. As pressões e interferências da sociedade civil organizada nas agendas de pesquisas sobre a doença, a constatação até então não imaginável de que a sociedade moderna não estava completamente protegida das doenças infecciosas, e de que a tecnologia médica não era infalível, são aspectos debatidos nesse capítulo. A autora reflete acerca dos dados que demonstram os limites da ciência, a burocracia institucional, os preconceitos dos pesquisadores e a falta de financiamento para questões de pesquisa mais sociais em Aids/HIV.

O capítulo III introduz o papel das agências globais na organização do enfrentamento contra a Aids, principalmente, o da Organização Mundial de Saúde (OMS), que, segundo a autora, "não apenas promoveu a coordenação de uma ação contra a epidemia à escala global, planetária, como deu bastante atenção à importância das lutas sociais geradas pelas próprias pessoas com Sida (Aids)" (p. 76).

Instigante a análise da autora em relação ao papel da OMS na primeira década da epidemia de Aids/HIV no mundo e de como tal organização, através de seus programas globais, publicações, encontros e congressos internacionais, proporcionou o intercâmbio de conhecimento entre diversas áreas e disciplinas, bem como entre as sociedades acadêmicas dos países de 'terceiro mundo' e as do 'primeiro mundo'. Esse importante papel da OMS no início da doença parece, de acordo com Cristiana Bastos, ter se retraído no começo da década de 1990 em decorrência de algumas modificações em setores da Organização.

O capítulo IV contextualiza as respostas brasileiras no enfrentamento à Aids/HIV com o objetivo de estudar a articulação entre estas e as respostas globais. A autora justifica a escolha do Brasil por causa da "vitalidade da pesquisa médica local", além do potencial dos estudos nos campos de imunologia, de epidemiologia social e de ciências sociais em saúde na problemática da Aids/HIV.

A vasta pesquisa em Aids/HIV em diversos campos no Brasil, principalmente estudos já consagrados como os de Richard Parker, Jane Galvão, Silvia Ramos e Kenneth Camargo Jr., bem como os da própria autora apóiam a análise dos dados apresentados nesse capítulo. $\mathrm{O}$ contexto político e social da chegada da epidemia, a formação das 
ONGs e a sua relação com as instituições acadêmicas, com o governo e com as organizações sociais são aspectos abordados e sensivelmente analisados.

A leitura até esse ponto da obra de Cristiana Bastos anuncia a necessidade da dimensão explorada no capítulo $\mathrm{V}$, ou seja, como as relações entre os espaços de produção, circulação e legitimação de saberes em Aids/HIV se traduzem em um outro espaço, o da assistência aos portadores da doença. O leitor é introduzido à experiência local da unidade especial para tratamento de Aids/HIV em um hospital universitário brasileiro, com todas as suas dificuldades.

A experiênciade profissionais médicos na relação com portadores e doentes vindos de realidades diversas - e com participação diferenciada nos produtos da ciência -, os relatos de profissionais de saúde a respeito da assistência prestada aos usuários da unidade hospitalar, os conhecimentos disciplinares e a 'utopia' da circulação global e internacional de informação e conhecimentos foram pontos relevantes que a autora utilizou para analisar a produção do conhecimento em Aids/ HIV, como também para investigar o acesso a tal produção na 'ponta' da realidade da epidemia.

O capítulo VI encerra o corpo analítico do livro com uma reflexão importante acerca da produção científica, no caso focando a Aids/HIV, em um país de contradições e desigualdades históricas como o Brasil. Os contrastes da coexistência de laboratórios e equipamentos sofisticados com a impossibilidade de mantê-los, a falta de financiamento em pesquisas de problemas seculares de saúde, a compra de antivirais em oposição à escassez de medicamentos básicos desenham um cenário que, nas palavras da autora, "é o rosto do mundo contemporâneo ... uma recriação constante de centros e periferias, centros flexíveis e móveis, periferias geradas pelo processo de modernização, lado a lado, uns dentro dos outros" (p. 202).

No capítulo VI a autora discute ainda a metáfora da 'guerra' utilizada historicamente para falar de doenças infecciosas e microrganismos, tanto do ponto de vista do sistema imunológico humano, quanto do 'combate' à doença e ao seu agente. A autora indica a necessidade de superar o modelo bélico que caracterizou a percepção oficial da Aids/ HIV. Concordamos com Cristiana Bastos em relação à dificuldade de superar essa percepção: “já que está ainda na ordem do dia, melhor serve a imagética bélica e militarizada para descrever, explicar e agir no corpo doente do que um imaginário pacífico de sistemas flexíveis e redes cognitivas" (p. 217).

Pedimos permissão a Cristiana Bastos para introduzir aqui uma refle-xão suscitada pelo dinamismo de seu trabalho. A metáfora da guerra e a utilização de termos como 'combate', 'luta' e 'defesa', tão presentes na linguagem científica ao tratar da Aids/HIV, se revestiram, algumas vezes, da idéia da 'doença crônica', como bem apontam Fee e Krieger (1993) na segunda década da doença. A tentativa de ajustar a Aids/HIV ao pa-radigma da doença crônica, com ações individuais de prevenção e com um estilo de vida saudável, adequou-se pouquíssimo à Aids/HIV em sua dimensão social abrangente. Nessa perspectiva, outra vez a doen-ça é do 'outro' e, como doença crônica, 
marca as desigualdades sociais 'crônicas', que são toleradas na medida em que só 'o outro' é quem morre.

As conclusões do estudo apresentadas nesse livro apontam algumas questões fundamentais. Nos centros urbanos do Primeiro Mundo, a produção de conhecimento em Aids/HIV e seu consenso passaram a incluir parceiros sociais do movimento ativista, cenário motivado mais pela pressão deste do que pela abertura daqueles. O apoio da OMS teve um papel crucial na organização e definição de respostas sociais à Aids/ HIV com diferentes características locais, mas também na produção de conhecimento 'dependente' no período estudado graças a esforços globais que se resumem em retórica diante da tecnologia de ponta dos centros desenvolvidos de pesquisa, tendo em vista a fragmentação institucional e disciplinar.

A autora ressalta dois campos de conhecimento que escapam, no Brasil, à tendência de conhecimento 'dependente', a saber, a imunologia e a epidemiologia social. Em consonância com a autora, indicamos a importância do fortalecimento da epidemiologia social, corrente da disciplina desenvolvida por pesquisadores latino-americanos nas décadas de 1970 e 1980, que significou uma contracorrente aos estudos individualizados da epidemiologia clínica. No contexto dos estudos da Aids/HIV, a epidemiologia social é um importante instrumento analítico a ser resgatado para demonstrar a determinação social da doença, como são importantes também os aportes científicos advindos das ciências humanas.

Muito já foi produzido sobre Aids/HIV no Brasil e no mundo. Os estudos de aspectos sociais, políticos, históricos e antropológicos da epidemia formam uma parte significativa, suscitada pela imensa rede de significações e implicações humanas que a Aids teceu nas últimas duas décadas.

A Aids provoca a discussão de vários aspectos, muito deles metafóricos, que foram socialmente construídos nos últimos 25 anos. Os limites tecnológicos, as desigualdades sociais, a intolerância diante das diferenças e, em contrapartida, o apoio solidário de homens e mulheres tornaram-se transparentes no decorrer desse tempo, e tais aspectos estão sempre presentes nas análises sobre a Aids/HIV.

Cristiana Bastos, com o seu livro Ciência, poder, aç̧ão: as respostas à Sida, soma ricas reflexões ao corpo científico sobre a Aids, com um tema ainda pouco enfrentado, ao examinar os 'bastidores' da produção de conhecimento sobre a infecção e as relações de poder, de legitimidade e de interesse que determinaram o estabelecimento de consensos científicos, a circulação e apropriação de tais saberes e a legitimação de centros de referências de conhecimento.

A experiência da produção de conhecimento em relação à epidemia explicitada pela pesquisa de Cristiana Bastos no período estudado enuncia a possibilidade de uma herança de solidariedade no processo de consenso e na relação dos grandes centros de pesquisa do Primeiro Mundo com seus pares científicos e com os movimentos sociais. Em tempos de resistência a medicamentos antivirais, de crescimento de novos casos de Aids/HIV nas regiões mais pobres do planeta e de recrudescimento de preconceitos, é necessário recuperar a experiência 
dos primeiros anos do aparecimento da doença. Pesquisas e reflexões em Aids/HIV na perspectiva do conhecimento complexo e solidário podem ser o caminho para ações mais humanitárias perante a Aids/ HIV na sociedade contemporânea e globalizada.

\section{REFERÊNCIAS BIBLIOGRÁFICAS}

Morin, Edgar (org.) A religação dos saberes: o desafio do século XXI.

2002

2. ed. Rio de Janeiro: Bertrand Brasil.

Fee, E.; Krieger, N. The emerging histories of Aids: three successive paradigms.

1993 History and philosophy of the life sciences, Baltimore, v. 15, n. 3, p. 459-87.

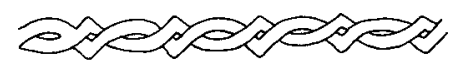




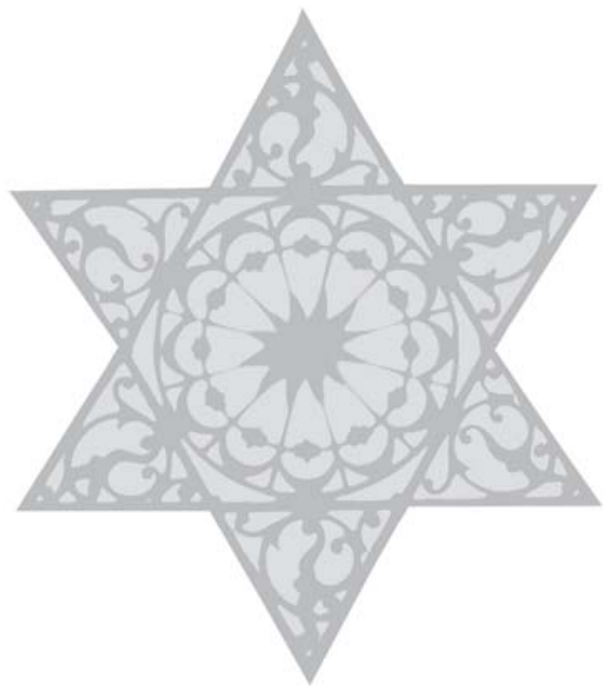

